\title{
Evaluation of the Treadmill Stress Testing for Risk Stratification after Acute Myocardial Infarction
}

\author{
Celso Blacher, Waldomiro Manfroi, Brisa Simões Fernandes
}

Porto Alegre, RS - Brazil

The recent decline in postinfarction mortality reflects the success of the most recent therapeutical proposals incorporated into clinical practice ${ }^{1}$. Despite this evolutional enhancement, mostly due to the use of thrombolytic agents, an increase in the recurrence of thrombotic phenomena, such as reinfarction and unstable angina, has occurred creating the need for strategies that adequately identify the patients with higher probability of an unfavorable outcome ${ }^{2}$.

The current evolution of acute myocardial infarction has resulted in changes in the clinical characteristics of the patients referred for the provocative tests for ischemia. These clinical characteristics were clearly identified by the professionals involved in treating acute myocardial infarction, who needed to reassess the previously existing concepts regarding these tests ${ }^{3}$. This led to the spread of the routine performance of coronary angiography after acute myocardial infarction before hospital discharge ${ }^{4}$. In 1987, research carried out among American cardiologists revealed that $86 \%$ of them had adopted this management in patients who had received thrombolytic agents ${ }^{4-6}$.

The TIMI II study ${ }^{5}$ was designed to compare the routine use of coronary angiography prior to hospital discharge with the more conservative management of only those patients who had a clinical indication. All patients were treated during the acute phase with recombinant tissue plasminogen activator (r-TPA) within the first 4 hours of pain onset. In the group undergoing the invasive procedure, 1.636 patients underwent coronary angiography and prophylactic angioplasty when it was anatomically feasible 18 to 48 hours after administration of the thrombolytic agent. In the group treated conservatively, 1.626 patients were clinically followed up and only those patients with signs of ischemia during hospital stay, either spontaneous or triggered by the treadmill stress test, were referred for coronary angiography. No statistically significant difference between the two groups was observed in regard to mortality or acute myocardial infarction and the ejection fraction at rest

Universidade Federal do Rio Grande do Sul and Santa Casa de Porto Alegre Mailing address: Celso Blacher - Rua Murilo Furtado, 287/601 - 90470-440 Porto Alegre, RS, Brazil or during exercise on the $42^{\text {nd }}$ postinfarction day. In the oneyear evaluation, no difference in the rate of new infarction or mortality occurred between the groups ${ }^{4}$. During this period of time, a larger number of hospital admissions due to cardiac events and coronary angiography was observed in those patients undergoing the conservative treatment, but the total number of coronary angiographies was still $40 \%$ smaller than that reported for the group undergoing the invasive treatment ${ }^{4}$.

Evidence obtained in the TIMI II study was fundamental in defining the results obtained in both managements, reducing the impulse to use invasive techniques in all patients.

Risk stratification after acute myocardial infarction The major indicators of a bad prognosis after an acute myocardial infarction evaluated in studies of risk stratification are the following: 1) reduction in ventricular function;2) residual myocardial ischemia; and 3) substrate for severe arrhythmias with risk of life. In regard to the prognosis of future events, the patients may be divided into 3 groups defined by their clinical findings ${ }^{1}$. Approximately $20 \%$ to $25 \%$ of the patients have the 3 types of indicators, are considered high risk and have a 1 -year mortality rate of $24 \%$ to $45 \%$. An intermediate group with one or two indicators accounts for $25 \%$ of the patients and has a mortality rate ranging from $15 \%$ to $20 \%$ in the first year. The third group accounts for $50 \%$ to $55 \%$ of the patients, evolves with no complications, and has a favorable prognosis with a 1 -year mortality rate of $1 \%$ to $3 \%{ }^{1}$.

The authors agree that the clinical criteria used for risk stratification in acute myocardial infarction continue to have the same value they had before the current treatment of this entity ${ }^{1,2,7-11}$. The TIMI II study was also very important in emphasizing the traditional clinical predictors because it used them in its classification of patients with and without low risk at the moment of randomization ${ }^{9,12}$.

Data necessary for the initial evaluation are predominantly clinical. Estimation of ventricular function does not need specific tests when used for prognostic finality in the majority of patients; it may be inferred through a simple rule. An ejection fraction higher than $40 \%$ will be present in those patients with the following characteristics: 1) an electrocardiogram that may be interpreted;2) absence of a previous infarction with the Q-wave; 3) no history of heart 
failure; 4) a current clinical finding that is not an acute myocardial infarction of the anterior wall. The positive predictive value of this rule is greater than $0.98^{13}$.

Indication of coronary angiography - Coronary angiography (or even the noninvasive test) is not indicated in patients to whom revascularization is not an option, either because of coexistent morbid conditions or because of the patient's preference. Those patients with clinical complications, therefore with clear high risk for future events, are usually candidates for catheterization. On the other hand, the use of coronary angiography or noninvasive tests in low-risk patients is still controversial ${ }^{8}$.

Arguments favoring the use of noninvasive tests are supported by the evidence that this strategy has the same results regarding reinfarction and mortality as compared with patients undergoing routine coronary angiography with a smaller number of invasive tests and revascularization $^{4,8,14-16}$. Those supporting routine coronary angiography emphasize the low accuracy of noninvasive tests, the low statistical power and the biases of selection of the studies carried out ${ }^{8,17,18}$, in addition to the better quality of life of those patients undergoing coronary angiography ${ }^{19}$.

Treadmill stress testing - Important studies carried out around 1980 showed that patients with abnormal results in low level exercise tests performed prior to hospital discharge had a mean 1-year mortality rate of $19 \%$ versus $2.6 \%$ for the patients with normal tests ${ }^{9}$. These are results of a time when the current therapeutical resources were not available and, therefore, the patients had more severe disease with a worse prognosis and a higher number of events during their evolution. In such a situation, tests with moderate accuracy had significant clinical value. Even before mortality rate after acute myocardial infarction underwent a significant fall, the value of treadmill stress testing as a predictor of risk had already been questioned ${ }^{9}$.

In the TIMI II study, either the patients managed through invasive strategies or those conservatively treated underwent treadmill stress testing prior to hospital discharge. Of the 3,339 randomized patients, 2,502 (75\%) underwent the test as follows: 1,168 patients in the invasiveapproach group and 1,187 patients in the conservativeapproach group. The patients who did not undergo the test differed from the others for the following reasons: they were older, mostly women, and they had more severe disease. Among the patients not undergoing the test, 59.2\% of those included in the conservative strategy and $52.5 \%$ of those invasively treated had one or more events (reinfarction, new anginal pain, or heart failure) within the 14 days at the hospital. These values were significantly smaller for the patients undergoing the test ${ }^{20}$.

One-year mortality among the patients conservatively treated was $0.6 \%$ and $2.4 \%$, depending on the presence or absence of depression of the ST-segment during treadmill stress testing (relative risk $0.2 ; \mathrm{p}=0.13$ ). The concept of relative risk is used for this and it corresponds to the comparison of the incidence of the event observed in the exposed population with that of the event observed in the nonexposed population ${ }^{21}$. For evaluation of depression of the ST-segment or angina, the values were $1.4 \%$ and $2.3 \%$ (relative risk of $0.6 ; \mathrm{p}=0.39$ ). Patients in the conservative treatment group with abnormal tests were referred for coronary angiography and, in many cases, for revascularization. These results only showed that the conservative strategy is safe and can reduce complications. However, nothing can be concluded in regard to the prognostic value of treadmill stress testing, because the evolution of the patients was altered by the study project itself. Among the patients referred for the invasive strategy, the presence of depression of the ST-segment showed a tendency toward a higher 1-year mortality rate (relative risk $=2.8 \% ; \mathrm{p}=0.06$ ). Approximately $50 \%$ of the studies were carried out after angioplasty, rendering a better evaluation of the prognostic value of the tests in this group difficult. The mortality rate was very low (1.4\% in the invasive group and $2.3 \%$ in the conservative group) because in the analysis the deaths prior to the $14^{\text {th }}$ day, a cut-off date for the performance of the treadmill stress test, were not considered. The relatively low incidence of events limited the statistical power to detect differences in prognosis related to the results of the treadmill stress test ${ }^{20}$.

Data obtained in the GISSI-2 study ${ }^{22}$ were analyzed to reassess the prognostic value of treadmill stress testing in a large population (around 10,000 patients, of whom, more than 6,000 underwent treadmill stress testing) with acute myocardial infarction treated with the currently recommended therapeutics (thrombolytic agents for all patients, acetylsalicylic acid in $84 \%$ of the patients, and intravenous betablockers in 48\%). One of the most important findings was the confirmation that the impossibility of undergoing treadmill stress testing was a strong indicator of a negative prognosis (6-month mortality of 7.1\% for those patients not undergoing the test, of $1.7 \%$ for those patients with positive results, and of $0.9 \%$ for those patients with negative results). The multivariate statistical analysis confirmed the only two independent indicators of increased mortality in 6 months: ischemia induced by exercise accompanied by angina, and low capacity of exercise (relative risk of 2.07, confidence interval of $95 \%=1.02-4.23$; and relative risk of 1.78 , confidence interval of $95 \%=1.06-2.99$, respectively). To clarify, the confidence interval quantifies the accuracy with which means and proportions obtained in the samples estimate the same parameters in the population, in addition to assessing the amplitude of plausible values originated in the difference between two means and proportions in different samples ${ }^{23}$.

Shaw et $\mathrm{al}^{7}$ carried out a meta-analysis, which summarizes the research on a topic using structured methods ${ }^{24}$, to evaluate the relation between the abnormal result of the noninvasive tests and the prognosis of the patients after an acute myocardial infarction. This meta-analysis comprised 54 articles published from 1980 to 1995 , including almost 20,000 patients. In spite of the fact that only 18 out of these 54 articles reported studies of patients treated with throm- 
bolytic agents, this meta-analysis offers the best evidence about the accuracy of noninvasive tests used to estimate life expectancy. Articles reporting on the stress electrocardiogram (28 studies and 15.613 patients) showed a high odds ratio, which is defined as the chance of a patient being exposed divided by the chances of a control being exposed ${ }^{25}$, for cardiovascular death in patients with depression of the STsegment $>1 \mathrm{~mm}$ (odds ratio 1.7; confidence interval of $95 \%$ 1.2-2.5), impairment of the systolic pressure (odds ratio 4.0; confidence interval of $95 \%$ 2.5-6.3) or limited duration of the exercise (odds ratio 4.0; confidence interval of $95 \%$ 1.9-8.4). The positive predictive value for the different treadmill stress parameters in regard to cardiovascular death was very low, varying from 0.04 to 0.11 and in regard to death and reinfarction from 0.16 to 0.25 . The negative predictive value, with an opposite behavior, varied from 0.94 to 0.98 for death, and from 0.88 to 0.91 for death or reinfarction ${ }^{7}$.

Therefore, the changes in the treadmill stress test usually used for prognostic evaluation after acute myocardial infarction are those that show ischemia, such as changes in the ST-segment, with a higher appraisal of the changes that occur with low loads and are accompanied by angina, and those changes indicating reduction in ventricular function, such as low exercise capacity and abnormal behavior of the blood pressure (this latter may not have an independent value).

Patients treated with thrombolytic agents have a lower mortality rate, but the risk of new ischemic events is increased. Thrombolytic therapeutics exposes the patient to the potential risk of reocclusion. It is not reasonable to expect that treadmill stress testing, which aims to identify reversible ischemia and severe ventricular dysfunction, will be able to predict an acute thrombotic occlusion, especially because occlusion can be independent from the degree of coronary stenosis $^{2,26}$. This explains partially the difficulty of the test in predicting future events.

Comparison between the accuracy of treadmill stress testing and other noninvasive methods - In addition to stress electrocardiography, the major noninvasive methods used to stratify the risk after an acute myocardial infarction are the following: stress myocardial scintigraphy, pharmacological stress myocardial scintigraphy, stress radionuclide ventriculography, and stress and pharmacological stress echocardiographies. Accuracy of the diverse parameters evaluated through these methods is similar to that of the treadmill stress test, with little if any additional information added to data obtained with this conventional examination, mainly regarding the positive and negative predictive values (table I). The best results obtained for the positive predictive value are those related to identification of a new dyssynergia on the stress echocardiogram $(0.48)$ and an ejection fraction $\leq 40 \%$ at the exercise peak, assessed through radiocardiography (0.31). The results of negative predictive value differ little from those obtained through treadmill stress testing (table I) ${ }^{7}$. However, it is important to emphasize that this evidence was obtained from a meta-analysis, which is a study where the populations and methods applied are different, impairing the power of the comparative analysis ${ }^{24}$.
Methods - Some technical not always well defined characteristics may influence the results and safety of treadmill stress testing, such as: performance of symptom limited and low level exercise testing, valorization of the socalled inconclusive tests, the best moment for performing the test, and suspension of drugs that may interfere with the results.

Symptom-limited versus low level exercise testing TIMI II trial, which established the possibility of evaluating patients after acute myocardial infarction through noninvasive management, used a low level exercise protocol ${ }^{4,5,20}$.

In another study ${ }^{27}, 202$ patients with uncomplicated acute myocardial infarction, 115 of whom had received thrombolytic agents, underwent two treadmill stress tests on subsequent days and in an alternate way through randomization. One of the tests was interrupted at 5METS or $70 \%$ of the maximum frequency for the age, while the other was interrupted according to symptoms, electrocardiographic or physical examination changes. Symptomlimited testing exhibited a longer exercise time $(554 \pm 209 \mathrm{~s}$ versus $389 \pm 125 \mathrm{~s}, \mathrm{p}<0.0001)$, reached higher loads $(5.7 \pm 1.8$ METs versus 4.2 \pm 1.1 METs; $p<0.0001)$ and a higher heart rate $(121 \pm 20$ versus $108 \pm 4 \mathrm{bpm} ; \mathrm{p}<0.0001)$. Patients with depression of the ST-segment $\geq 1 \mathrm{~mm}$ increased from 56 in the low level exercise testing to 89 in the symptom-limited testing $(\mathrm{p}<0.0001)$ and patients with depression of the STsegment $\geq 2 \mathrm{~mm}$, increased from 22 to 41 , an increase of $86 \%$ $(\mathrm{p}<0.0001)$. The authors conclude that the symptom-limited test is associated with an ischemic response approximately two times higher than that of the low level exercise testing. In regard to safety, only two patients showed complications temporally related to the testing: one of them had a nonfatal acute myocardial infarction 5 hours after completing a symptom-limited test.

Another study ${ }^{28}$ showed results of 150 patients with uncomplicated acute myocardial infarction, who were assessed in the same test at $70 \%$ of the foreseen maximum

\begin{tabular}{|c|c|c|c|c|}
\hline \multirow[t]{2}{*}{ Tests } & \multirow{2}{*}{$\begin{array}{c}\text { Cardiac death } \\
\text { PPV }\end{array}$} & \multicolumn{3}{|c|}{ Cardiac death/AMI } \\
\hline & & NPV & PPV & NPV \\
\hline Treadmill stress testing & $0.04-0.11$ & $0.94-0.98$ & $0.16-0.21$ & $0.89-0.91$ \\
\hline Stress myo. scint. & $0.07-0.7$ & 0.98 & $0.16-0.17$ & $0.95-0.97$ \\
\hline Stress radion. & 0.10 & 0.90 & $0.17-0.19$ & $0.90-0.91$ \\
\hline Stress myo. scint. & $0.15-0.27$ & $0.94-0.98$ & $0.17-0.31$ & $0.91-0.94$ \\
\hline Stress echo & 0.18 & 1.0 & $0.14-0.48$ & $0.86-0.92$ \\
\hline Pharm-stress echo. & 0.05 & 0.98 & 0.08 & 0.94 \\
\hline \multicolumn{5}{|c|}{$\begin{array}{l}\text { Stress myo. scint.- stress myocardial scintigraphy; pharm. stress myo. } \\
\text { scint.- pharmacological stress myocardial scintigraphy; stress radion. } \\
\text { ventriculog.- stress radionuclide ventriculography; stress echo.- stress } \\
\text { echocardiography; pharm. stress echo.- pharmacological stress } \\
\text { echocardiography; AMI- acute myocardial infarction; PPV- positive } \\
\text { predictive value; NPV-negative predictive value. Variability of the values } \\
\text { of PPV and NPV in a same testing is due to the different results obtained } \\
\text { with the various parameters studied in each type of testing (modified table } \\
\text { from Shaw et al }{ }^{7} \text { ). }\end{array}$} \\
\hline
\end{tabular}


heart rate and at the end of the symptom-limited test. Results were positive in $23 \%$ of the patients at the end of the first stage and in $40 \%$ when the tests were symptom-limited $(\mathrm{p}<0.001)$. During a follow-up period of $15 \pm 5$ months, a significantly higher number of patients with symptom-limited tests showed events $(\mathrm{p}<0.001)$. No complications from the tests were reported. The tests were considered safe and when performed with a symptom-limited protocol more patients with ischemia were identified with a higher risk of future events who could benefit from precocious intervention.

The guidelines of the American Heart Association and of the American College of Cardiology suggest that symptom-limited testing performed after acute myocardial infarction is safe. But, taking into account that the prognostic value of the ST-segment alterations in higher exercise levels is yet uncertain, the AHA/ACC guidelines caution that the use of these symptom-limited tests may lead to an unnecessary number of cardiac catheterization ${ }^{29}$.

Inconclusive testings - An important and not very clear question regards patients who have their tests interrupted due to fatigue before reaching heart rates considered effective, without pathological alterations, especially when on drugs that modify the chronotropic response. Would this be a normal symptom-limited study or an ineffective test? While most of the authors do not properly clarify this point and seem to interpret these patients as having completed the test $^{27,28}$, the GISSI- 2 protocol defines a heart rate higher than $85 \%$ of the heart rate foreseen for the age, and a test that does not reach this objective, without signs of ischemia, as nondiagnostic. Such patients have an intermediate relative risk for events in 6 months compared with patients with positive and negative tests. Inclusion of nondiagnostic tests as negative is considered by the authors as one of the reasons for confusion of the results ${ }^{22}$.

Time for performing the testing - Precocious treadmill stress testing after acute myocardial infarction is safe with an incidence of $0.03 \%$ for death, $0.09 \%$ for nonfatal acute myocardial infarction or recovered cardiac arrest, and $1.4 \%$ for severe arrhythmias ${ }^{30}$.

Time for performing the tests varied in each study $2,4,22,31,32$. Traditional low level exercise testing may usually be performed in patients who evolve without complications between the $3^{\text {rd }}$ and the $5^{\text {th }}$ day after the acute myocardial infarction. Symptom-limited testing is indicated from the $5^{\text {th }}$ day on ${ }^{27}$.

Suspension of the drugs - In the evaluation of the GISSI-2 trial data, drugs were suspended to increase the effectiveness of the tests; however, in other studies, patients were examined with varied treatments or with no treatment at all ${ }^{2,4,22,31,32}$. This is another reason for confusion that may pass unnoticed in the assessment of the published results and clinical use of testing.

Conclusions - Patients with contraindication for treadmill stress testing after acute myocardial infarction (persistent ischemia, hemodynamic impairment, severe arrhythmias and noncardiac diseases that prevent test performance) constitute a group of older patients, with a higher proportion of women, patients with more severe disease, and with a significantly higher risk than patients undergoing testing.

Treadmill stress testing may be used to stratify the risk of patients after an acute myocardial infarction in conservative management with risks in general similar to those of coronary angiography.

Patients with negative tests have low risk of developing events (high negative predictive value) and may be kept under clinical observation. On the other hand, patients with positive results should be referred for a better evaluation, usually with coronary angiography, which may, in many cases, not confirm the presence of severe coronary lesions (low positive predictive value).

Whenever possible, symptom-limited testing should be performed in the absence of specific medications to enhance the capacity of the testing to reveal myocardial ischemia.

Those tests with positive results only with high exercise levels, those with electrocardiographic criteria for ischemia without symptoms (silent ischemia) or those interrupted due to fatigue without ischemic alterations and without reaching the recommended heart rate (nondiagnostic testings) have a smaller prognostic value and should be carefully evaluated. Many times, confirmation of the results through other noninvasive techniques, prior to a possible coronary angiography, is recommended.

\section{References}

1. Figueiredo VM. Risk stratification after acute myocardial infarction. Wich sudies are best? Postgrad Med 1996; 99: 207-14.

2. Stevenson R, Umachandran V, Ranjadayalan K, Wilkinson P, Marchant B, Timmis AD. Reassessment of treadmill stress testing for risk stratification in patients with acute myocardial infarction treated with thrombolysis. Br Heart J 1993; 70 : 415-20.

3. Lavie CJ, Gibbons RJ, Zinsmeister AR, Gersh BJ. Interpreting results of exercise studies after acute myocardial infarction altered by thrombolytic therapy, coronary angioplasty or bypass. Am J Cardiol 1991; 67: 116-20.

4. Rogers WJ, Babb JD, Baim DS, et al. Selective versus routine predischarge co- ronary arteriography after therapy with recombinant tissue-type plasminogen activator, heparin and aspirin for acute myocardial infarction. J Am Coll Cardiol 1991; 17: 1007-16.

5. The TIMI Study Group. Comparison of invasive and conservative strategies after treatment with intravenous tissue plasminogen activator in acute myocardial infarction. N Engl J Med 1989; 320: 618-27.

6. Hlatky MA, Cotugno HE, Mark DB, O'Connor C, Califf RM, Pryor DB. Trends in physician management of uncomplicated acute myocardial infarction, 1970 to 1987. Am J Cardiol 1988; 61: 515-18.

7. Shaw LJ, Peterson ED, Kesler K, Hasselblad V, Califf RM. A metaanalysis of predischarge risk stratification after acute myocardial infarction with stress elec- 
tocardiographic, myocardial perfusion and ventricular imaging. Am J Cardiol 1996; 78: 1327-37.

8. Peterson ED, Shaw LJ, Califf RM. Risk stratification after myocardial infarction. Ann Intern Med 1997; 126: 561-82.

9. Reeder GS, Gibbons RJ. Acute myocardial infarction: risk stratification in the thrombolytic era. Mayo Clin Proc 1995; 70: 87-94.

10. DeBusk RF, Blomqvist CG, Kouchoukos NT, Luepker RV. Identification and treatment of low risk patients after acute myocardial infaction and coronary arthery bypass graft surgery. N Engl J Med 1986; 314: 161-6.

11. Krone RJ. The role of risk stratification in the early management of myocardial infarction. Ann Intern Med 1992; 116: 223-37.

12. Hillis LD, Forman S, Braunwald E, and TIMI II Investigators. Risk stratification before thrombolytic therapy in patients with acute myocardial infarction. J Am Coll Cardiol 1990; 16: 313-5.

13. Silver MT, Rose GA, Paul SD, O’Donnell CJ, O' Gara PT, Eagle KA. A clinical rule to predict left ventricular ejection fraction in patients after myocardial infarction. Ann Inten Med 1994; 121: 750-6.

14. Michels KB, Yusuf S. Does PTCA in acute myocardial infarction affect mortality and reinfarction rates? A quantitative overview (meta-analysis) of the randomized clinical trials. Circulation 1995; 91: 476-85.

15. Ross J, Gilpin EA, Madsen EB, et al. A decision scheme for coronary angiography after acute myocardial infarction. Circulation 1989; 79: 292-303.

16. Favaloro, RG. Critical analysis of coronary artery bypass graft surgery: a 30year journey. J Am Coll Cardiol 1998: 1B-63B

17. Simões MV, Maciel BC, Castro RBP, et al. Estratificação prognóstica em sobreviventes ao infarto agudo do miocárdio. Teste ergométrico versus cinecoronariografia. Arq Bras Cardiol 1997; 68: 167-74.

18. Bodenheimer MM. Risk stratification in coronary disease: a contrary viewpoint. Ann Intern Med 1992; 116: 927-36.

19. Mark DB, Naylor, Hlatky MA, et al. Use of medical resources and quality of life after acute myocardial infarction in Canada and the United States. NEngl J Med 1994; 331: 1130-5.

20. Chaitman BR, McMahon RP, Terrin M, et al. Impact of treatment strategy on predischarge exercise test in the Thrombolysis in Myocardial Infarction (TIMI) II Trial. Am J Cardiol 1993; 71: 131-8.
21. Fuchs FD, Wannmacher L. Métodos de Investigação Farmacológico-Clínica. In: Fuchs FD, Wannmacher L, eds. Farmacologia Clínica-Fundamentos da Terapêutica Racional. $2^{a}$ Ed. Rio de Janeiro: Guanabara Koogan, 1998: 12.

22. Villella A, Maggioni AP, Villella M, et al. Prognostic significance of maximal exercise testing after myocardial infarction treated with thrombolytic agents: the GISSI-2 data-base. Lancet 1995; 346: 523-9.

23. Huttly S, Fuchs FD. Fundamentos de Bioestatística. In: Fuchs FD, Wannmacher L, eds. Farmacologia Clínica - Fundamentos da Terapêutica Racional. $2^{a}$ Ed. Rio de Janeiro: Guanabara Koogan, 1998: 25.

24. Fletcher RH, Fletcher SW, Wagner EH. Sumarizando. In: Fletcher RH, Fletcher SW, Wagner EH, eds. Epidemiologia Clínica: elementos Essenciais. $3^{a}$ ed. Porto Alegre: Artes Médicas, 1996: 265.

25. Fletcher RH, Fletcher SW, Wagner EH. Estudando Casos. In: Fletcher RH, Fletcher SW, Wagner EH, eds. Epidemiologia Clínica: elementos Essenciais. $3^{\text {a }}$. ed. Porto Alegre: Artes Médicas, 1996: 225.

26. Diamond GA. Postinfarction risk stratification. Is preventive war winnable? JAMA 1993; 269: 2418-9.

27. Juneau M, Colles $P$, Théroux $P$, et al. Symptom-limited versus low level exercise testing before hospital discharge after acute myocardial infarction. J Am Coll Cardiol 1992; 20: 927-33.

28. Jain A, Myers H, Sapin PM, O'Rourke RA. Comparision of symptom-limited and low level exercise tolerance tests early after myocardial infarction. J Am Coll Cardiol 1993; 22: 1816-20.

29. American College of Cardiology/American Heart Association Task Force on Practice Guidelines (Committe on Management of Acute Myocardial Infarction). ACC/AHA guidelines for the management of patients with acute myocardial infarction. J Am Coll Cardiol 1996; 28: 1328-428.

30. Ramos S. Oteste ergométrico convencional no diagnóstico e prognóstico da doença arterial coronariana. Revista da Sociedade de Cardiologia do RGS 1998; 7: 11-8.

31. Théroux P, Waters DD, Halphen C, Debaisieux JC, Mizgala HF. Prognostic value of exercise testing soon after myocardial infarction. N Engl J Med 1979; 301 : 341-5.

32. Piccalò G, Pirelli S, Massa D, Cipriani M, Sarullo FM, De Vita C. Value of negative predischarge exercise testing in identifying patients of low risk after acute myocardial infarction treated by systemic thrombolysis. Am J Cardiol 1992; 70: 31-3. 